\title{
Whole genome amplification of the rust Puccinia striiformis f. sp. tritici from single spores
}

\author{
Yanchun Wang a , Mingqi Zhu ${ }^{\text {a }}$, Rong Zhang a , Hanli Yang a, Yang Wang a, Guangyu Sun a,*, \\ Shelin Jin ${ }^{\mathrm{b}}$, Tom Hsiang ${ }^{\mathrm{c}}$ \\ a College of Plant Protection, Northwest AEF University, Yangling, Shaanxi, China \\ b Institute of Plant Protection, Gansu Agricultural Science Academy, Lanzhou, Gansu, China \\ c Department of Environmental Biology, University of Guelph, Guelph, Ontario, Canada N1G 2W1
}

\section{A R T I C L E I N F O}

\section{Article history:}

Received 14 January 2009

Accepted 11 February 2009

Available online 20 February 2009

\section{Keywords:}

$\beta$-tubulin gene

Multiple displacement amplification

rDNA-ITS

Single-spore

Whole genome amplification

\begin{abstract}
A B S T R A C T
Rust fungi are obligate parasites and cannot be routinely cultured to obtain sufficient biomass for DNA extractions. Multiple displacement amplification (MDA) was demonstrated in this study for whole genome amplification from single spores of the rust fungus, Puccinia striiformis. The genomic DNA coverage and fidelity of this method was evaluated by PCR amplification and sequencing of two genetic markers: portions of the multi-copy nuclear ribosomal DNA internal transcribed spacer region (ITS) and the single copy $\beta$ tubulin gene from two geographical diverse isolates. Our results show that MDA is a valuable tool for whole genome amplification from single spores, and we propose that MDA-amplified DNA can be used for molecular genetic analysis of the wheat yellow rust fungus.
\end{abstract}

(c) 2009 Elsevier B.V. All rights reserved.

\section{Introduction}

Puccinia striiformis f. sp. tritici, is a highly specialized obligately biotrophic pathogen (Roose-Amsaleg et al., 2002) that causes yellow rust of wheat. It is one of the most devastating diseases of wheat throughout the world and is considered a major problem in wheat production, particularly in China (Shan et al., 1998). Because of their nature as obligate parasites, rusts cannot be readily cultured on nutrient media, and the strict asexual propagation by uredospores has significantly hampered research from a molecular genetics viewpoint (Roose-Amsaleg et al., 2002). A basic requirement of molecular tools is the availability of suitable quality and sufficient quantity of DNA (Fernández-Ortuno et al., 2007). Although many molecular genetic analyses of fungi have been reported, studies of large populations of rust fungi are limited (Shan et al., 1998). Genomic DNA can be extracted from single uredospores (de Vallavieille-Pope et al., 1990) and subjected to amplification, however there are many disadvantages, such as low reproducibility, possible contamination by other organisms, and somatic hybridization among others.

DNA extraction from single spores requires a mechanical step to break up the spore wall, and then the suspension containing the crushed spores can be used directly for PCR, which has been described in the studies of the large-spored, multinucleate arbuscular mycor-

\footnotetext{
* Corresponding author. Tel.: +86 29 87092075; fax: +86 2987092075 . E-mail address: sgy@nwsuaf.edu.cn (G. Sun).
}

rhizal fungi (AMF) (Vanderkoornhuyse and Leyval, 1998; Schwarzott and SchuBler, 2001). The limited DNA content in a single spore may restrict analyses to only a few PCR amplifications. Moreover, PCR amplification often fails because of the variable efficiency of single spore DNA extractions (Gadkar and Rilling, 2005a), and hence this method cannot meet the needs of many research projects (Zhang et al., 1992; Peng et al., 2007).

Another approach is to utilize whole genome amplification (WGA) strategies which can produce abundant quantities of DNA from a limited source, even single spores (Gadkar and Rilling, 2005a). Previously, several PCR-based WGA techniques have been developed, such as primer extension preamplification (PEP) (Zhang et al., 1992), and degenerate oligonucleotide primed PCR (DOP-PCR) (Telenius et al., 1992). Although PCR-based WGA techniques have been successfully applied to whole genome amplification even from single cells, these methods have limitations, such as amplification bias, generation of relatively short DNA fragments and possible introduction of mutations into the amplified products (Peng et al., 2007).

Recently, multiple displacement amplification (MDA) has provided high yield, faithful representation of the original template, and complete coverage of the genome in a relatively simple procedure. MDA has been used for accurate WGA from single cells and spores (Handyside et al., 2004; Hellani et al., 2005; Paez et al., 2004; Raghunathan et al., 2005; Spits et al., 2006; Wang et al., 2004).

To develop methodology that can shed some light on the molecular genetics of wheat stripe rust fungi, we have used MDA to amplify the 
whole genome from single spores. We then tested the genome coverage and fidelity of the MDA process by sequencing of two genetic markers: portions of the multi-copy nuclear ribosomal DNA internal transcribed spacer (rDNA-ITS) region and the single copy $\beta$-tubulin gene. Our results show that amplification of genomic DNA from a single spore using MDA is feasible.

\section{Materials and method}

\subsection{Fungal strains}

Two isolates of $P$. striiformis $\mathrm{f}$. sp. tritici, strain Baihua from the USA and strain Shui5 from Gansu, China, were used in this study. Each isolate was cloned from a single uredospore by a series of monouredospore transfers on wheat seedlings (de Vallavieille-Pope et al., 1990).

\subsection{Isolation of total DNA}

Total DNA (T-DNA) was extracted according to Roose-Amsaleg et al. (2002) with slight modifications. Approximately $1 \mathrm{mg}$ nongerminated uredospores were crushed in a $1.5 \mathrm{ml}$ microcentrifuge tube with $50 \mu \mathrm{l}$ of extraction buffer [100 mM Tris- $\mathrm{HCl}, \mathrm{pH} 9.0 ; 20 \mathrm{mM}$ EDTA, pH 8.0; $1.4 \mathrm{mM} \mathrm{NaCl} ; 2 \%$ cetyltrimethylammonium bromide $(\mathrm{CTAB})]$ by using plastic pestles (Bio Basic Inc. Markham, Ontario, Canada). Then, $550 \mu \mathrm{l}$ of extraction buffer was added to each tube, and the solution was incubated for $2 \mathrm{~h}$ at $65{ }^{\circ} \mathrm{C}$. Proteins were denatured and removed by repeated extractions with $600 \mu$ Tris saturated phenol:chloroform:isoamyl alcohol (25:24:1, v/v/v). Phases were separated by centrifugation, the aqueous phase removed and DNA precipitated with $700 \mu \mathrm{l}$ of isopropanol. DNA was pelleted by alcohol precipitation, dried and resuspended in $40 \mu \mathrm{l}$ of Tris-EDTA buffer (10 mM Tris-HCl, pH 7.6; $1 \mathrm{mM}$ EDTA). An aliquot of the extracted DNA was separated by electrophoresis on $1 \%$ agarose gels for visualization and quantification.

\subsection{Isolation of single spores and whole genome amplification from single spores}

The single spore extraction method followed Hahn et al. (2000) with slight modifications. A $0.5 \mathrm{~mm}$ diameter nickel-chromium vaccination needle (Hexing A\&F Science Equipment Factory, Jiangsu, China) was flamed with ethanol. A glass slide was immersed into ethanol, and then air dried. A few spores were picked up with the vaccination needle and applied onto the glass slide, and gently teased apart. A transfer needle was made from a $200 \mu \mathrm{l}$ microcentrifuge tube (Axygen PCR-02-C, Shanghai BioScience, Shanghai, China), by first cutting the tube along its length. Repeated gentle shaving of one half with a sharp scalpel resulted in needles approximately $3 \mathrm{~mm}$ long and $100 \mu \mathrm{m}$ wide at the tip. These minute shards were picked up at one end with tweezers, and the tip was used to pick up single spores from the glass slide while viewed at $60 \times$ under a dissecting microscope (Leica MZ9.5, All Microscopy, Beijing, China). The shard with the single spore was then placed into a PCR tube.

Whole genome amplification of single spores was carried out using the REPLI-g Mini Kit (Gene Company Ltd., Beijing, China) following manufacturer's instructions with slight modifications. A $3.5 \mu \mathrm{l}$ aliquot of denaturation buffer was added into the microcentrifuge tube containing the target single spore and $3 \mu \mathrm{l}$ phosphate buffered saline (PBS) included in the kit. This solution was vortexmixed, centrifuged briefly, incubated for $10 \mathrm{~min}$ on ice, and then $3.5 \mu \mathrm{l}$ of a stop solution was added. To the denatured sample, $40 \mu \mathrm{l}$ of a blend of REPLI-g Mini DNA polymerase and REPLI-g Mini reaction buffer was added, mixed and incubated at $30{ }^{\circ} \mathrm{C}$ for $16 \mathrm{~h}$. After incubation, the enzyme was heat-inactivated at $65^{\circ} \mathrm{C}$. The amplified product was run out on a $1 \%$ agarose gel to verify the reaction. The remaining amplified DNA was stored at $4{ }^{\circ} \mathrm{C}$ for short-term use or at $-20{ }^{\circ} \mathrm{C}$ for longer-term periods.

\subsection{Primer design and PCR amplification}

The $\beta$-tubulin primers were designed with the Primer Premier 5.0 (Premier Biosoft International, Palo Alto, California, USA), using $\beta$-tubulin gene sequences from GenBank (Aecidium brachycomes, EF570791.1; Puccinia aegopodii, DQ983205.1; P. bistortae, EF570794.1; P. calthae, EF570798.1; P. cnici, EF570803.1; P. dioica, EF570804.1; P. fergussonii, DQ983210.1; P. fergussonii, EF570806.1; P. hieracii, EF570811.1; P. lagenophorae, EF635884.1; P. ludwigii, EF570816.1; P. luzulae, EF570819.1; P. morrisoni, EF570841.1; P. obscura, EF570818.1; P. ribesii-caricis, EF570802.1; P. rupestris, DQ983207.1; P. saccardoi, EF570835.1; P. septentrionalis, EF570838.1; P. stylidii, EF570844.1; P. vaginatae, EF570846.1; P. uliginosa, EF570801.1; P. xanthii, EF635885.1; and Uromyces sommerfeltii, EF570859.1). To amplify the ITS region, the primers ITS1-F (Gardes and Bruns, 1993) and ITS4 (White et al., 1990) were used. The PCR reactions were set up in a $25 \mu \mathrm{l}$ volume containing $2 \mu \mathrm{l}$ of DNA extract, $2 \mathrm{mM} \mathrm{MgCl} 2,1 \mathrm{U}$ of DNA polymerase, $1 \mu \mathrm{M}$ of each of the primer pair, $200 \mu \mathrm{M}$ of dNTP mixture and $2.5 \mu \mathrm{l}$ of $10 \times$ reaction buffer. The cycling conditions were as follows: for rDNA-ITS, $94{ }^{\circ} \mathrm{C}$ for $3 \mathrm{~min}$, followed by 34 cycles of $94{ }^{\circ} \mathrm{C}$ for $30 \mathrm{~s}, 52{ }^{\circ} \mathrm{C}$ for $30 \mathrm{~s}$ and $72{ }^{\circ} \mathrm{C}$ for $1 \mathrm{~min}$ and a final extension of $72{ }^{\circ} \mathrm{C}$ for $7 \mathrm{~min}$; for $\beta$-tubulin, $94{ }^{\circ} \mathrm{C}$ for $5 \mathrm{~min}$, followed by 20 cycles of $94{ }^{\circ} \mathrm{C}$ for $1 \mathrm{~min}, 65^{\circ} \mathrm{C}$ for $1 \mathrm{~min}$ (with a decrease of the annealing temperature every cycle by $1{ }^{\circ} \mathrm{C}$ ) and $72{ }^{\circ} \mathrm{C}$ for $1 \mathrm{~min}$, followed 20 cycles of $94{ }^{\circ} \mathrm{C}$ for $1 \mathrm{~min}, 45^{\circ} \mathrm{C}$ for $1 \mathrm{~min}$ and $72{ }^{\circ} \mathrm{C}$ for $1 \mathrm{~min}$ and a final extension of $72{ }^{\circ} \mathrm{C}$ for $10 \mathrm{~min}$. The PCR products were analyzed by electrophoresis on $1 \%$ agarose gels to visualize and quantify the reaction products.

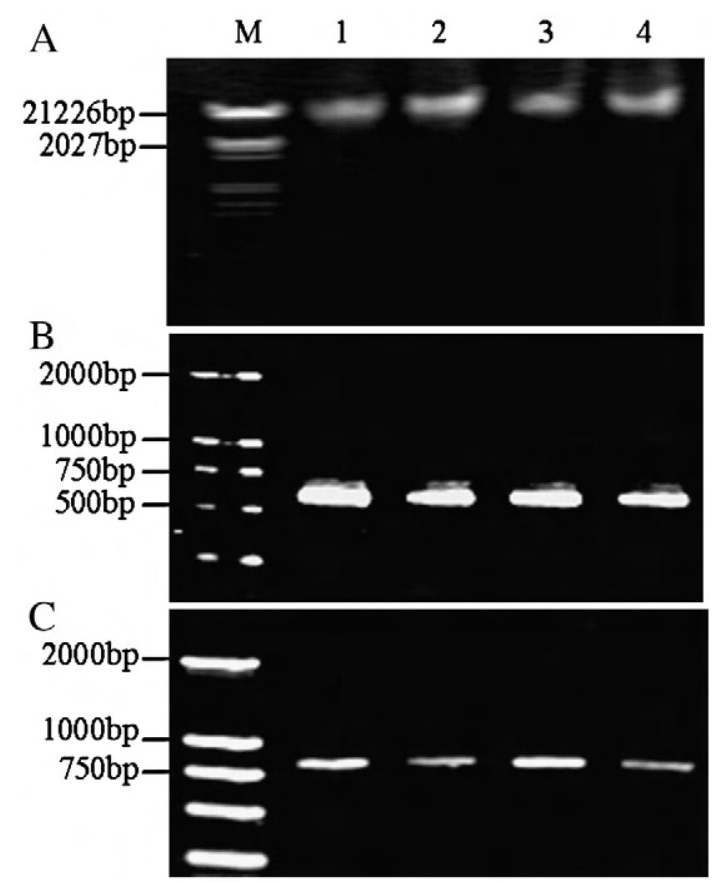

Fig. 1. Whole genome amplification (WGA) of single spores of Puccinia striiformis by multiple displacement amplification (MDA) and PCR amplification of genetic markers from single-spore WGA reaction templates. A. Total DNA extractions $(2 \mu \mathrm{l})$ and WGA reaction products $(2 \mu \mathrm{l})$ fractionated on a $1 \%$ agarose gel. B. Amplification of the ITS regions of nuclear rDNA (ITS) from total DNA and single-spore WGA-DNA. C. Amplification of a fragment of the $\beta$-tubulin gene from total DNA and single-spore WGA-DNA. Lane M: molecular size markers: A. גDNA/HindIII+EcoR I Marker; B and C. DL2000 marker. Lanes 1 and 3, total DNA of P. striiformis strain Baihua and Shui5 genomic DNA, respectively. Lanes 2 and 4, whole genome amplification products of single spores of $P$. striiformis strains Baihua and Shui5, respectively. 


\subsection{Sequence analysis}

The PCR products were purified using the HQ\&Q Gel Extraction Kit (U-gene Biotechnology, Anhui, China), cloned into the pMD19-T vector (TaKaRa Biotechnology Co. Ltd., Dalian, China) as described by the manufacturer's protocols, and sequenced by dideoxy sequencing method (Sangon, Shanghai, China) in both forward and reverse directions. The sequence data were viewed using Chromas software
Baihua (T-DNA) Baihua (S-DNA) Shuis (S-DNA) Shuis (T-DNA)

Baihua (T-DNA) Baihua (S-DNA) shuis (S-DNA) Shuis (T-DNA)

Baihua (T-DNA) Baihua (S-DNA) Shuis (S-DNA) Shuis (T-DNA)

Baihua (T-DNA) Baihua (S-DNA) Shuis (S-DNA) Shuis (T-DNA)

Baihua (T-DNA) Baihua (S-DNA) shuis (S-DNA) shuis (T-DNA)

Baihua (T-DNA) Baihua (S-DNA) Shuis (S-DNA) Shuis (T-DNA)

Baihua (T-DNA) Baihua (S-DNA) Shuis (S-DNA) Shuis (T-DNA)

Baihua (T-DNA) Baihua (S-DNA) Shuis (S-DNA) Shuis (T-DNA)

Baihua (T-DNA) Baihua (S-DNA) Shuis (S-DNA) Shuis (T-DNA)

Baihua (T-DNA) Baihua (S-DNA) Shuis (S-DNA) shuis (T-DNA)

Baihua (T-DNA) Baihua (S-DNA) Shuis (S-DNA) shuis (T-DNA)

Baihua (T-DNA) Baihua (S-DNA) Shuis (S-DNA) Shuis (T-DNA)
CTTGGTCATTTAGAGGAAGTAAAAGTCGTAACAAGGTTTCCGTAGGTGAACCTGCGGAAG 60 CTTGGTCATTTAGAGGAAGTAAAAGTCGTAACAAGGTTTCCGTAGGTGAACCTGCGGAAG 60 CTTGGTCATTTAGAGGAAGTAAAAGTCGTAACAAGGTTTCCGTAGGTGAACCTGCGGAAG 60 CTTGGTCATTTAGAGGAAGTAAAAGTCGTAACAAGGTTTCCGTAGGTGAACCTGCGGAAG 60

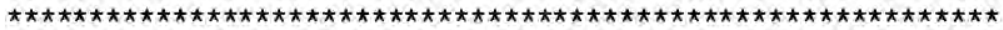
GATCATTATTAAAAGAACTAGAGTGCACTTTATTGTGGCTCGACCCCTTTTAAAAATCTC 120 GATCATTATTAAAAGAACTAGAGTGCACTTTATTGTGGCTCGACCCCTTTTAAAAATCTC 120 GATCATTATTAAAAGAACTAGAGTGCACTTTATTGTGGCTCGACCCCTTTTAAAAATCTC 120 GATCATTATTAAAAGAACTAGAGTGCACTTTATTGTGGCTCGACCCCTTTTAAAAATCTC 120

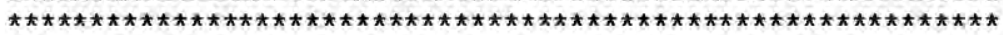
ACCCAAACTTTTAAGACTTGGTTGCATGATTTGAAAGAATCATTGCAATTGAGTAGACGT 180 ACCCAAACTTTTAAGACTTGGTTGCATGATTTGAAAGAATCATTGCAATTGAGTAGACGT 180 ACCCAAACTTTTAAGACTTGGTTGCATGATTTGAAAGAATCATTGCAATTGAGTAGACGT 180 ACCCAAACTTTTAAGACTTGGTTGCATGATTTGAAAGAATCATTGCAATTGAGTAGACGT 180

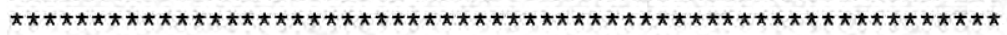
AACTTCTTTATTGAATGTTGCATTACCCTCCCTTTTTTTTTTT---ATTAAAAATTACAC 237 AACTTCT"TTATTGAATGTTGCATTACCCTCCCTTTT"TTTTTTTT--ATTAAAAATTACAC 238 AACTTCTTTATTGAATGTTGCATTACCCTCCCTTTTTTTTTTTT--ATTAAAAATTACAC 238 AACTTCTTTATTGAATGTTGCATTACCCTCCCTTTTTTTTTTTTTTATTAAAAATTACAC 240

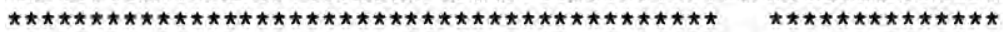

AAAACACAAGTTTAAATGAATGTAACCAAACCTTTAATTATAAATAACTTTTAACAATGG 297 AAAACACAAGTTTAAATGAATGTAACCAAACCTTTAATTATAAATAACTTTTAACAATGG 298 AAAACACAAGTTTAAATGAATGTAACCAAACCTTTAATTATAAATAACTTTTAACAATGG 298 AAAACACAAGTTTAAATGAATGTAACCAAACCTTTAATTATAAATAACTTTTAACAATGG 300

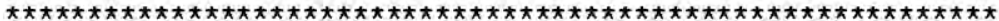
ATCTCTAGGCTCTCACATCGATGAAGAACACAGTGAAATGTGATAAGTAATGTGAATTGC $35 ?$ ATCTCTAGGCTCTCACATCGATGAAGAACACAGTGAAATGTGATAAGTAATGTGAATTGC 358 ATCTCTAGGCTCTCACATCGATGAAGAACACAGTGAAATGTGATAAGTAATGTGAATTGC 358 ATCTCTAGGCTCTCACATCGATGAAGAACACAGTGAAATGTGATAAGTAATGTGAATTGC 360

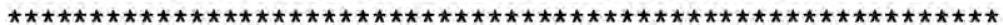

AGAATTCAGTGAATCATCGAATCTTTGAACGCACCTTGCGCCTTTTGGTATTCCAAAAGG 417 AGAATTCAGTGAATCATCGAATCTTTGAACGCACCTTGCGCCTTTTGGTATTCCAAAAGG 418 AGAATTCAGTGAATCATCGAATCTTTGAACGCACCTTGCGCCTTTTGGTATTCCAAAAGG 418 AGAATTCAGTGAATCATCGAATCTTTGAACGCACCTTGCGCCTTTTGGTATTCCAAAAGG 420

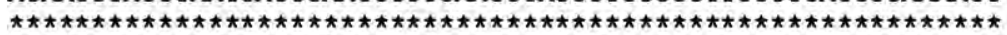
CACACCTGTTTGAGTGTCATGAAACCCTCTCATTAAATAATTTTGATTAATTATTTTCAA 477 CACACCTGTTTGAGTGTCATGAAACCCTCTCATTAAATAATT"TTGATTAATTATTTTCAA 478 CACACCTGTTTGAGTGTCATGAAACCCTCTCATTAAATAATTTTGATTAATTATTTTCAA 478 CACACCTGTTTGAGTGTCATGAAACCCTCTCATTAAATAATTTTGATTAATTATTTTCAA 480

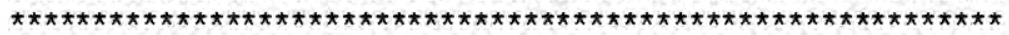
TGGATGTTGAGTGCTGCTGTAATTAGCTCACTTTAAATATATAAGTCACTTTTCTATAAG 537 TGGATGTTGAGTGCTGCTGTAATTAGCTCACTTTAAATATATAAGTCACTTTTCTATAAG 538 TGGATGTTGAGTGCTGCTGTAATTAGCTCACTTTAAATATATAAGTCACTTTTCTATAAG 538 TGGATGTTGAGTGCTGCTGTAATTAGCTCACTTTAAATATATAAGTCACTTTTCTATAAG 540

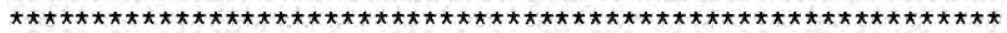
TTGGATTGACTTGGTGTAATAATTTTATCATCACATCAAGGATTGTAGCAATACTGCCAT 597 TTGGATTGACTTGGTGTAATAATTTTATCATCACATCAAGGATTGTAGCAATACTGCCAT 598 TTGGATTGACTTGGTGTAATAATTTTATCATCACATCAAGGATTGTAGCAATACTGCCAT 598 TTGGATTGACTTGGTGTAATAATTTTATCATCACATCAAGGATTGTAGCAATACTGCCAT 600

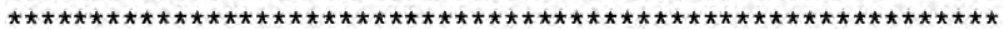
CTTATTTAAGGGAGACTCCTAAAAACCCAATTTTAACCTTAAGACCTCAAATCAGGTGGG 657 CTTATTTAAGGGAGACTCCTAAAAACCCAATTTTAACCTTAAGACCTCAAATCAGGTGGG 658 CTTATTTAAGGGAGACTCCTAAAAACCCAATTTTAACCTTAAGACCTCAAATCAGGTGGG 658 CTTATTTAAGGGAGACTCCTAAAAACCCAATTTTAACCTTAAGACCTCAAATCAGGTGGG 660

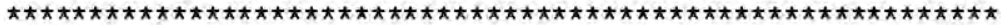
ACTACCCGCTGAACTTAAGCATATCAATAAGCGGAGGA 695 ACTACCCGCTGAACTTAAGCATATCAATAAGCGGAGGA 696 ACTACCCGCTGAACTTAAGCATATCAATAAGCGGAGGA 696 ACTACCCGCTGAACTTAAGCATATCAATAAGCGGAGGA 698

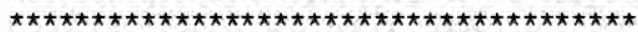

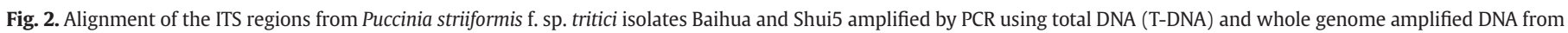
single spores (S-DNA) as templates. The sequences have been deposited in GenBank (EU924747, FJ224375, FJ224376, and FJ224378). 
Baihua (T-DNA)

Baihua (S-DNA)

Shuis (S-DNA)

Shuis (T-DNA)

Baihua (T-DNA)

Baihua (S-DNA)

Shuis (S-DNA)

Shuis (T-DNA)

Baihua (T-DNA)

Baihua (S-DNA)

Shuis (S-DNA)

Shuis (T-DNA)

Baihua (T-DNA) Baihua (S-DNA) Shuis (S-DNA) shuis (T-DNA)

Bainua (T-DNA) Baihua (S-DNA) Shuis (S-DNA) shuis (T-DNA)

Baihua (T-DNA) Bainua (S-DNA) Shuis (9-DNA) Shuis (T-DNA)

Baihua (T-DNA) Baihua (S-DNA) Shuis (S-DNA) shuis (T-DNA)

Baihua (T-DNA) Baihua (S-DNA) Shuis (S-DNA) shuis (T-DNA)

Baihua (T-DNA) Baihua (S-DNA) Shuis (S-DNA) Shuis (T-DNA)

Baihua (T-DNA) Baihua (S-DNA) shuis (S-DNA) Shuis (T DNA)

Baihua (T-DNA) Baihua (S-DNA) Shuis (S-DNA) Shuis (T-DNA)

Baihua (T-DNA) Baihua (S-DNA) Shuis (S-DNA)

shuis (T-DNA)

Baihua (T-DNA) Baihua (S-DNA) Shuis (S-DNA) shuis (T-DNA)

Baihua (T-DNA) Baihua (S-DNA) shuis (9-DNA) shuis (T-DNA)
CGAATTAGTTGACTCCGTACTGGATGTCGTCCGCAAAGAAGCAGAAGGATGTGACTGTCT 60 CGAATTAGTTGACTCCGTACTGGATGTCGTCCGCAAAGAAGCAGAAGGATGTGACTGTCT 60 CGAATTAGTTGACTCCGTACTGGATGTCGTCCGCA.AAGAAGCAGAAGGATGTGACTGTCT 60 CGAATTAGTTGACTCCGTACTGGATGTCGTCCGCAAAGAAGCAGAAGGATGTGACTGTCT 60

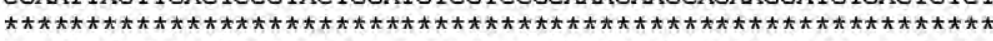
TCAAGGATTTCAGATCACCCACTCCCTCGGTGGTGGAACTGGTGCCGGAATGGGTACCTT 120 TCAAGGATTTCAGATCACCCACTCCCTCGGTGGTGGAACTGGTGCCGGAATGGGTACCTT 120 TCAAGGATTTCAGATCACCCACTCCCTCGGTGGTGGAACTGGTGCCGGAATGGGTACCTT 120 TCAAGGATTTCAGATCACCCACTCCCTCGGTGGTGGAACTGGTGCCGGAATGGGTACCTT 120

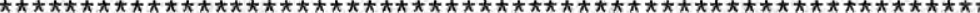
GTTGATTTCCAAGATCCGAGAAGAATTTCCTGATCGTATGATGGCCACCTTCTCCGTTGT 180 GTTGATTTCCAAGATCCGAGAAGAATTTCCTGATCGTATGATGGCCACCTTCTCCGTTGT 180 GTTGATTTCCAAGATCCGAGAAGAATTTCCTGATCGTATGATGGCCACCTTCTCCGTTGT 180 GTTGATTTCCAAGATCCGAGAAGAATTTCCTGATCGTATGATGGCCACCTTCTCCGTTGT 180

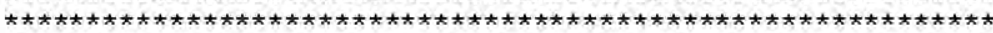

CCCCTCGCCTAAGGTGTCTGATACCGTTGTCGAGCCTTACAACGCCACCTTGTCGGTTCA 240 CCCCTCGCCTAAGGTGTCTGATACCGTTGTCGAGCCTTACAACGCCACCTTGTCGGTTCA 240 CCCCTCGCCTAAGGTGTCTGATACCGTTGTCGAGCCTTACAACGCCACCTTGTCGGTTCA 240 CCCCTCGCCTAAGGTGTCTGATACCGTTGTCGAGCCTTACAACGCCACCTTGTCGGTTCA 240

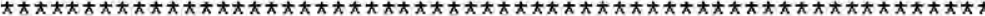

TCAACTGGTCGAAAACTCGGACGAAACCTTTTGTATCGATAACGAGGCGCTTTACGATAT 300 TCAACTGGTCGAAAACTCGGACGAAACCTTTTGTATCGATAACGAGGCGCTTTACGATAT 300 TCAACTGGTCGAAAACTCGGACGAAACCTTTTGTATCGATAACGAGGCGCTTTACGATAT 300 TCAACTGGTCGAAAACTCGGACGAAACCTTTTGTATCGATAACGAGGCGCTTTACGATAT 300

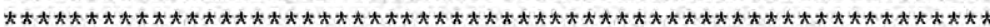

CTGCTTCCGCACCCTGAAATTGGCTACACCTACCTACGGTGACCTCAATCACTTGGTCTC 360 CTGCTTCCGCACCCTGAAATTGGCTACACCTACCTACGGTGACCTCAATCACTTGGTCTC 360 CTGCTTCCGCACCCTGAAATTGGCTACACCTACCTACGGTGACCTCAATCACTTGGTCTC 360 CTGCTTCCGCACCCTGAAATTGGCTACACCTACCTACGGTGACCTCAATCACTTGGTCTC 360

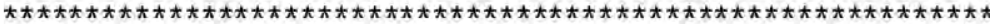

GATCGTCATGAGTGGGATCACCACCTGTCTTCGATTCCCCGGTCAGCTTAACTCTGATCT 420 GATCGTCATGAGTGGGATCACCACCTGTCTTCGATTCCCCGGTCAGCTTAACTCTGATCT 420 GATCGTCATGAGTGGGATCACCACCTGTCTTCGATTCCCCGGTCAGCTTAACTCTGATCT 420 GATCGTCATGAGTGGGATCACCACCTGTCTTCGATTCCCCGGTCAGCTTAACTCTGATCT 420

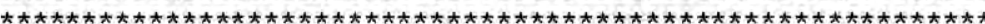
CCGTAAACTAGCTGTCAACATGGTTCCTTTCCCTCGATTGCACTTCTTCATGGTCGGATT 400 CCGTAAACTAGCTGTCAACATGGTTCCTTTCCCTCGATTGCACTTCTTCATGGTCGGATT 480 CCGTAAACTAGCTGTCAACATGGTTCCTTTCCCTCGATTGCACTTCTTCATGGTCGGATT 480 CCGTAAACTAGCTGTCAACATGGTTCCTTTCCCTCGATTGCACTTCTTCATGGTCGGATT 480

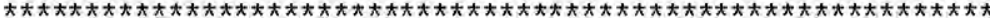
CGCTCCGCTTACCGCTCGTGGAAGCCAACAATACCGGGCAATCACCGTCCCAGAGTTGAC 540 CGCTCCGCTTACCGCTCGTGGAAGCCAACAATACCGGGCAATCACCGTCCCAGAGTTGAC 540 CGCTCCGCTTACCGCTCGTGGAAGCCAACAATACCGGGCAATCACCGTCCCAGAGTTGAC 540 CGCTCCGCTTACCGCTCGTGGAAGCCAACAATACCGGGCAATCACCGTCCCAGAGTTGAC 540

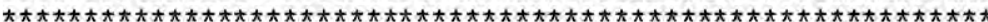

ATCGCAAATGTTTGATGCCAAGAACATGATGGCCGCTTCTGACCCGAGACACGGCCGATA 600 ATCGCAAATGTTTGATGCCAAGAACATGATGGCCGCTTCTGACCCGAGACACGGCCGATA 600 ATCGCAAATGTTTGATGCCAAGAACATGATGGCCGCTTCTGACCCGAGACACGGCCGATA 600 ATCGCAAATGTTTGATGCCAAGAACATGATGGCCGCTTCTGACCCGAGACACGGCCGATA 600

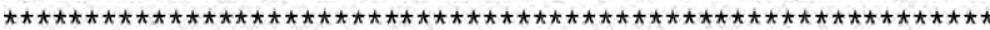
CTTGACCGTTGCCGCTTACTTCCGTGGAAAGGTTTCCATGAAAGAAGTCGAAGAGAACAT 660 CTTGACCGTTGCCGCTTACTTCCGTGGAAAGGTTTCCATGAAAGAAGTCGAAGAGAACAT 660 CTTGACCGTTGCCGCTTACTTCCGTGGAAAGGTTTCCATGAAAGAAGTCGAAGAGAACAT 660 CTTGACCGTTGCCGCTTACTTCCGTGGAAAGGTTTCCATGAAAGAAGTCGAAGAGAACAT 660

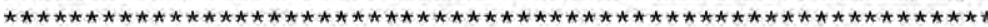

GCTGTCCGTTCAAAGCAAGAACTCCAACTACTTTGTTGAGTGGAGTAAGTCCGGCTTTCG 720 GCTGTCCGTTCAAAGCAAGAACTCCAACTACTTTGTTGAGTGGAGTAAGTCCGGCTTTCG 720 GCTGTCCGTTCAAAGCAAGAACTCCAACTACTTTGTTGAGTGGAGTAAGTCCGGCTTTCG 720 GCTGTCCGTTCAAAGCAAGAACTCCAACTACTTTGTTGAGTGGAGTAAGTCCGGCTTTCG 720

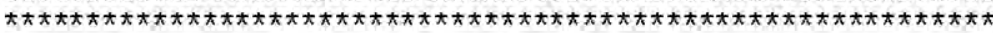
TCTGTTTCTCTCATGTCGGCTTATGATTATGATACTCATATCTGTGAACACTTGGTATAA 780 TCTGTTTCTCTCATGTCGGCTTATGATTATGATACTCATATCTGTGAACACTTGGTATAA 700 TCTGTTTCTCTCATGTCGGCTTATGATTATGATACTCATATCTGTGAACACTTGGTATAA 780 TCTGTTTCTCTCATGTCGGCTTATGATTATGATACTCATATCTGTGAACACTTGGTATAA 780

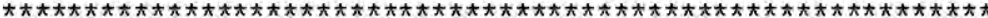
CCTCAGTTCCGAACAACGTC 800 CCTCAGTTCCGAACAACGTC 800 CCTCAGTTCCGAACAACGTC 800 CCTCAGTTCCGAACAACGTC 800

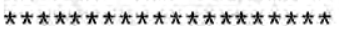

Fig. 3. Alignment of the $\beta$-tubulin gene from Puccinia striiformis f. sp. tritici isolates Baihua and Shui5 amplified by PCR using total DNA (T-DNA) or whole genome amplified DNA from single spores (S-DNA) as templates. The sequences have been deposited in GenBank (FJ612008, FJ612006, FJ612007, and FJ612005). 
version 2.3 (Technelysium, Queensland, Australia), and manually adjusted in a text editor, and subjected to BLASTN (Altschul et al., 1990) analysis against the GenBank NR database.

\section{Results}

\subsection{Whole genome amplification from single spores}

The WGA reactions were set up using the REPLI-g mini kit and singlespore denatured solution. An aliquot $(2 \mu \mathrm{l})$ of the reaction was run on an agarose gel and the amplification products were visualized. The singlespore WGA-DNA (S-DNA) was of similar size to that of extracted genomic DNA by conventional methods (over $20 \mathrm{~kb}$ ) (Fig. 1A).

\subsection{Primer design for $\beta$-tubulin and PCR analysis of specific genes}

The $\beta$-tubulin gene primers were designed based on existing sequences for $P$. striiformis in GenBank, and the primer sequences were as follows: TURustF: 5'-GTCAYTAYACYGARGGWGC-3', TURustR: $5^{\prime}$-TGTCACARTGDGCRRTTTG-3'. The primers were synthesized by the Generay Biotech Co., Ltd. (Shanghai, China).

The MDA generated samples were analyzed for fidelity to source by PCR amplification of two DNA markers, nuclear rDNA-ITS ( $700 \mathrm{bp}$, Fig. 1B), and a part of the $\beta$-tubulin gene ( 800 bp, Fig. 1C). As a positive control, these genes were also amplified from the genomic DNA extracts from multiple spores, allowing direct comparison of the efficiency of the single spore method. The size of bands and their intensity were similar for both the multi-spore and single-spore DNA extractions and amplifications. Over 100 separate DNA extractions from single spores using conventional methods were made to amplify these sequences, but no amplified DNA was observed.

\subsection{Sequence analysis of ITS and $\beta$-tubulin gene fragments}

To check the sequence fidelity of the method of amplification from whole genome DNA extractions of single spores of $P$. striiformis $\mathrm{f}$. $\mathrm{sp}$. tritici, the DNA fragments were sequenced in forward and reverse directions with the primers M13+ and M13 - situated in pMD19-T. Fig. 2 shows the alignments of the 700-bp ITS region from isolates Baihua and Shui5 amplified from total DNA (T-DNA) and whole genome DNA from single spores (S-DNA). The sequences from Baihua (T-DNA), Shui5 (T-DNA), Baihua (S-DNA), and Shui5 (S-DNA) have been deposited in GenBank (EU924747, FJ224375, FJ224376, and FJ224378). The sequence of ITS fragments amplified from T-DNA showed only a single mismatch with the sequence from S-DNA of Baihua. For Shui5, there were two mismatches between T-DNA and SDNA. The mismatches were all found in a poly $\mathrm{T}(>10)$ region.

A similar analysis was carried out for an 800-bp portion of the $\beta$-tubulin gene. The different sequence runs yielded the same results. Fig. 3 shows the alignments of the $\beta$-tubulin sequence from isolates Baihua and Shuis amplified from T-DNA and S-DNA. The sequences of Baihua (T-DNA), Shui5 (T-DNA), Baihua (S-DNA), and Shui5 (S-DNA) have been deposited in GenBank (FJ612008, FJ612006, FJ612007, and FJ612005). The sequences of $\beta$-tubulin fragments amplified from T-DNA and S-DNA were identical.

\section{Discussion}

There are several reasons for using DNA extracted from single spores for genetic analysis. First, it is difficult to produce a large number of spores because of time and expense. Secondly, it is difficult to ensure that spores are all genetically uniform even if attempts were made to collect from a single uredinium. Thirdly, using a single spore for DNA extraction allows for a reduced possibility of contamination by other organisms, such as cross-contamination in open pot cultures by other stripe rust isolates and potential somatic hybridization in the asexual reproduction process. Application of an efficient whole genome amplification method can overcome these inherent shortcomings when dealing with a non-culturable obligately parasitic organism.

The extraction of DNA from single spores of $P$. striiformis by the multiple displacement amplification (MDA) reaction is a suitable and reliable method to obtain DNA for genetic analysis. MDA relies upon the high fidelity and strand displacement ability of DNA polymerase of the bacteriophage phi29 (Esteban et al., 1993) and the exonuclease resistant random primers (Dean et al., 2001) to amplify DNA fragments of high molecular weight $\left(>10 \mathrm{~kb}\right.$ ) with low error rates $\left(<10^{-6}\right)$. After only a few hours, it can provide consistent DNA amplification even with very low amounts of starting template (Peng et al., 2007). The sensitivity is so high, that great care must be taken in picking up the desired single spore and throughout the extraction process, since any minute amounts of contaminating DNA would also be amplified.

The nuclear rDNA-ITS region is commonly used for the identification of many fungal species (Roose-Amsaleg et al., 2002), and is the most frequently sequenced region among fungi. This region is situated between the $18 \mathrm{~S}$ and $28 \mathrm{~S}$ ribosomal genes, which are found in multiple copy number in eukaryotes (Weider et al., 2005). In addition to a multicopy gene, we selected the $\beta$-tubulin gene because it also has been used frequently in fungal systematics (van der Merwe et al., 2007), and has single or low-copy number (Ayliffe et al., 2001). Only a single $\beta$-tubulin gene has been found among most fungi studied, but two $\beta$-tubulin genes have been found in the genomes of several ascomycota and the rust, Melampsora lini (Ayliffe et al., 2001). However, Wirsel et al. (2004) did not find evidence of a second copy in the rust, Uromyces fabae. We assume that the $\beta$-tubulin is a single-copy gene in P. striiformis, but more research is needed to confirm this.

For rDNA-ITS, up to two mismatches were found between T-DNA and S-DNA of the two isolates investigated. These differences may be real, since polymorphism has been observed in the multiple copies of rDNA sequences of rust fungi (Roose-Amsaleg et al., 2002). A single uredospore is a dikaryon composed of two haploid nuclei, and polymorphisms may exist between these two nuclei. Or these differences may have arisen during the PCR amplification and sequencing process. For the $\beta$-tubulin gene, the sequences of T-DNA and S-DNA were identical in multiple sequencing attempts, although the primer regions did show variability because degenerate primers were used.

Successful amplification of the multi-copy ITS region and the single copy $\beta$-tubulin gene in $P$. striiformis confirmed that the nuclear DNA was copied during the MDA reaction using single spores, while attempts at amplification of DNA from conventional single spore extractions never yielded any products. The band intensities of the ITS or $\beta$-tubulin amplicons using MDA of single spores were similar to those obtained using genomic DNA from multiple spores. Furthermore the gene sequences were almost identical confirming the genome coverage of the MDA technique. The MDA-synthesized template has been used for a diverse set of downstream applications such as allele amplification, single nucleotide polymorphism (SNP) analysis (Dean et al., 2002), restriction fragment length polymorphisms (RFLP) analysis (Gadkar and Rilling, 2005b), polymorphism discovery, single sperm typing, chromosome translocation, and gene mutation analysis (Jiang et al., 2005; Luthra and Medeiros, 2004; Murthy et al., 2005). Future research in these fields on $P$. striiformis $\mathrm{f}$. sp. tritici will be facilitated through the use of the MDA method, since it reliably amplified genomic DNA from a single fungal spore. The use of MDADNA makes it possible to perform large scale genetic analyses of single spores of the wheat yellow rust pathogen, and possibly of other rust pathogens and other obligately parasitic fungi.

\section{Acknowledgments}

This work was supported by the National Basic Research Program (2006CB100204), National Natural Science Foundation of China (30670013), the 111 Project from Education Ministry of China (No. 
B07049), the Program for Changjiang Scholars and Innovative Research Team in University (No. 200558 and IRT0748), and the Natural Sciences and Engineering Research Council of Canada.

\section{References}

Altschul, S.F., Gish, W., Miller, W., Myers, E.W., Lipman, D.J., 1990. Basic local alignment search tool. J. Mol. Biol. 215 (3), 403-410.

Ayliffe, M.A., Dodds, P.N., Lawrence, G.J., 2001. Characterisation of a beta-tubulin gene from Melampsora lini and comparison of fungal beta-tubulin genes. Mycol. Res. 105, 818-826.

de Vallavieille-Pope, C., Picard-Formery, H., Radulovic, S., Johnson, R., 1990. Specific resistance factors to yellow rust in seedlings of some French wheat varieties and races of Puccinia striiformis Westend. in France. Agronomie 10, 103-113.

Dean, F.B., Nelson, J.R., Giesler, T.L., Lasken, R.S., 2001. Rapid amplification of plasmid and phage DNA using phi29 DNA polymerase and multiply-primed rolling circle amplification. Genome Res. 11, 1095-1099.

Dean, F.B., Hosono, S., Fang, L., Wu, X., Faruqi, A.F., Bray-Ward, P., et al., 2002. Comprehensive human genome amplification using multiple displacement amplification. Proc. Natl. Acad. Sci. U.S.A. 99, 5261-5266.

Esteban, J.A., Salas, M., Blanco, L., 1993. Fidelity of the phi 29 DNA polymerase. Comparison between protein-primed initiation and DNA polymerization. J. Biol. Chem. 268, 2719-2726.

Fernández-Ortuno, D., Juan, A., de Vicente, T.A., Pérez-García, A., 2007. Multiple displacement amplification, a powerful tool for molecular genetic analysis of powdery mildew fungi. Curr. Genet. 51, 209-219.

Gadkar, V., Rilling, M.C., 2005a. Application of Phi29 DNA polymerase mediated whole genome amplification on single spores of arbuscular mycorrhizal (AM) fungi. FEMS Microbiol. Lett. 242, 65-71.

Gadkar, V., Rilling, M.C., 2005b. Suitability of genomic DNA synthesized by strand displacement amplification (SDA) for AFLP analysis: genotyping single spores of arbuscular mycorrhizal (AM) fungi. J. Microbiol. Methods 63, 157-164.

Gardes, M., Bruns, T.D., 1993. ITS primers with enhanced specificity for basidiomycetes application to the identification of mycorrhizae and rusts. Mol. Ecol. 2,113-118.

Hahn, S., Zhong, X.Y., Troeger, C., Burgemeister, R., Gloning, K., Holzgreve, W., 2000. Current applications of single-cell PCR. Cell. Mol. Life Sci. 57, 96-105.

Handyside, A.H., Robinson, M.D., Simpson, R.J., Omar, M.B., Omar, M.B., Shaw, M.A., et al., 2004. Isothermal whole genome amplification from single and small numbers of cells: a new era for preimplantation genetic diagnosis of inherited disease. Mol. Hum. Reprod. 10, 767-772.

Hellani, A., Coskun, S., Tbakhi, A., Al-Hassan, S., 2005. Clinical application of multiple displacement amplification in preimplantation genetic diagnosis. Reprod. Biomed. $10,376-380$.

Jiang, Z.W., Zhang, X.Q., Deka, R., Jin, L., 2005. Genome amplification of single sperm using multiple displacement amplification. Nucleic Acids Res. 33, e91.

Luthra, R., Medeiros, L.J., 2004. Isothermal multiple displacement amplification: a highly reliable approach for generating unlimited high molecular weight genomic DNA from clinical specimens. J. Mol. Diagn. 6, 236-242.
Murthy, K.K., Mahboubi, V.S., Santiago, A., Barragan, M.T., Knǒll, R., Schultheiss, H.-P., et al, 2005. Assessment of multiple displacement amplification for polymorphism discovery and haplotype determination at a highly polymorphic locus, MC1R. Hum. Mutat. 26 145-152.

Paez, J.G., Lin, M., Beroukhim, R., Lee, J.C., Zhao, X., Richter, D.J., et al., 2004. Genome coverage and sequence fidelity of phi29 polymerase-based multiple strand displacement whole genome amplification. Nucleic Acids Res. 18, e71.

Peng, W., Takabayashi, H., Ikawa, K., 2007. Whole genome amplification from single cells in preimplantation genetic diagnosis and prenatal diagnosis. Eur. J. Obstet. Gynecol. Reprod. Biol. 20, 13-20.

Raghunathan, A., Ferguson, H.R., Bornarth, C.J., Driscoll, M., Lasken, R.S., 2005. Genomic DNA amplification from a single bacterium. Appl. Environ. Microbiol. 71, 3342-3347.

Roose-Amsaleg, C., de Vallavieille-Pope, C., Brygoo, Y., Levis, C., 2002. Characterisation of a length polymorphism in the two intergenic spacers of ribosomal RNA in Puccinia striiformis f. sp. tritici, the causal agent wheat yellow rust. Mycol. Res. 106 (8), 918-924.

Shan, W.X., Chen, S.Y., Kang, Z.S., Wu, L.R., Li, Z.Q., 1998. Genetic diversity in Puccinia striiformis Westend. f. sp. tritici revealed by pathogen genome-specific repetitive sequence. Can. J. Bot. 76, 587-595.

Schwarzott, D., SchuBler, A., 2001. A simple and reliable method for SSU rRNA gene DNA extraction, amplification, and cloning from single AM fungal spores. Mycorrhiza 10 203-207.

Spits, C., Caignec, C.L., Rycke, M.D., Haute, L.V., Steirteghem, A.V., Liebaers, I., et al., 2006 Whole-genome multiple displacement amplification from single cells. Nat. Protoc. 1, 1965-1970.

Telenius, H., Carter, N.P., Bebb, C.E., Nordenskjold, M., Ponder, B.A., Tunnacliffe, A., 1992 Degenerate oligonucleotide-primed PCR: general amplification of target DNA by a single degenerate primer. Genomics 13, 718-725.

van der Merwe, M., Ericson, L., Walker, J., Thrall, P.H., Burdon, J.J., 2007. Evolutionary relationships among species of Puccinia and Uromyces (Pucciniaceae, Uredinales) inferred from partial protein coding gene phylogenies. Mycol. Res. 111, 163-175.

Vanderkoornhuyse, P., Leyval, C., 1998. SSU rDNA sequencing and PCR-fingerprinting reveal genetic variation within Glomus mosseae. Mycologia 90, 791-797.

Wang, G., Brennan, C., Rook, M., Wolfe, J.L., Leo, C., Chin, L., et al., 2004. Balanced-PCR amplification allows unbiased identification of genomic copy changes in minute cell and tissue samples. Nucleic Acids Res. 32, e76.

Weider, L.J., Elser, J.J., Crease, T.J., Mateos, M., Cotner, J.B., Markow, T.A., 2005. The functional significance of ribosomal (r)DNA variation: impacts on the evolutionary ecology of organisms. Annu. Rev. Ecol. Evol. Syst. 36, 219-242.

White, T.J., Bruns, T., Lee, S., Taylor, J., 1990. Amplification and direct sequencing of fungal ribosomal RNA genes for phylogenetics. In: Innis, M.A., Gelfand, D.H., Sninsky, J.J. White, T.J. (Eds.), PCR Protocols: a Guide to the Methods and Applications. Academic San Diego, pp. 315-322.

Wirsel, S.G.R., Voegele, R.T., Banninger, R., Mendgen, K.W., 2004. Cloning of beta-tubulin and succinate dehydrogenase genes from Uromyces fabae and establishing selection conditions for their use in transformation. Eur. J. Plant Pathol. 110, 767-777.

Zhang, L., Cui, X., Schmitt, K., Hubert, R., Navidi, W., Arnheim, N., 1992. Whole genome amplification from a single cell: implications for genetic analysis. Proc. Natl. Acad. Sci. U.S.A. 89, 5847-5851. 